\title{
Male parent birds exert more effort to reproduce in two desert passerines
}

\author{
Donghui Ma, Mengjie Lu, Zhichang Cheng, Xingnan Du, Xiaoyu Zou, Xingxing Yao and Xinkang Bao* (D)
}

\begin{abstract}
Background: Parental investment by birds is limited by the habitat environment, and a male parent increases its effort to reproduce in birds that live in high-altitude areas.

Methods: A study of the reproductive behaviour of the Saxaul Sparrow (Passer ammodendri) and the Isabelline Shrike (Lanius isabellinus) was carried out at the Gansu An'xi Extremely Arid Desert National Nature Reserve in northwest China to determine the reproductive input of passerine species in desert habitats.

Results: In Saxaul Sparrows, compared to the female parent, the male parent exhibited a significantly higher frequency of nest-defense behaviour (chirping and warning) during nesting, hatching and feeding periods. In addition, in comparison to the female parent, the male parent exhibited almost equal frequencies of nesting and incubation but fed nestlings significantly more times. Similar to the male sparrows, the feeding rates of the male Isabelline Shrikes were significantly higher than those of the females. The hatching rate and fledging rate of the Saxaul Sparrow on average in this study were 81.99 and $91.92 \%$, respectively, while those of the shrike were 69.00 and $96.53 \%$, respectively.
\end{abstract}

Conclusions: These two different passerine species living in the same desert environment exhibited the same trend in their reproductive investments. Adapting to desert environments is a strategy that may have evolved in passerines where male parent birds put more effort than females into reproduction to ensure high reproductive output.

Keywords: Behaviour, Isabelline Shrike, Parental investment, Reproductive strategy, Saxaul Sparrow

\section{Background}

Reproduction is one of the most important activities in the life history of birds and includes a series of activities, such as courting, nesting, mating, laying, hatching and brooding (Parish and Coulson 1998; Gross 2005). Every step of this process requires parents to expend considerable time and energy to ensure reproductive success (Trivers 1972). Usually, these expenditures are distinct in males versus females as there are parental trade-offs and different roles in breeding (Trivers 1974) that are affected by various factors (Sanz et al. 2000), such as parental body condition (van Noordwijk and de Jong 1986), number of offspring (Trivers 1974), partner contribution

*Correspondence: baoxk@lzu.edu.cn

School of Life Sciences, Lanzhou University, Lanzhou 730000, China
(Sanz et al. 2000; Horváthová et al. 2012), and habitat environment (Badyaev 1997; Wynne-Edwards 1998).

Furthermore, nestling survival rates rely on parental care, which is directly related to the environment of the breeding location. Parents increase their investment to compensate for the decline in reproductive success in birds, especially males, when resource availability declines (Badyaev 1997; Wynne-Edwards 1998). Ghalambor (2001) compared the proportion of female and male reproductive investments at different altitudes and found that the investments were positively correlated with altitude, especially in males. Therefore, do male birds that live in extremely arid desert environments increase their reproductive efforts to improve their reproductive success?

Shrikes (family Laniidae) are unique among passerines and have powerful bills, such as those of falcons; 
in addition, they feed like raptors. The Isabelline Shrike (Lanius isabellinus) is also an outstanding hunter that feeds on large insects and lizards. The Saxaul Sparrow (Passer ammodendri), which belongs to the Passeridae family, is a passerine species with less information published on it than on any other Passer species (Summers-Smith 1989). Both species are socially monogamous passerine birds with sexual dimorphism and are often distributed in the same areas. However, they have distinctly different characteristics. For instance, the Isabelline Shrike is a raptorial passerine that has a bowlshaped nest and hatches synchronously, while the Saxaul Sparrow is a passerine species that reproduces in caves or tangled, enclosed nests, live in groups and hatches asynchronously.

In this study, we compared the reproductive investments of the Saxaul Sparrow and the Isabelline Shrike, both living and breeding in the same habitat in an extremely arid desert, to interpret how desert passerine birds select breeding strategies to acclimatize to arid conditions.

\section{Methods \\ Study area}

The study area is located in the desert region of Central Asia near BeiQiaozi village $\left(40^{\circ} 21^{\prime} \mathrm{N}, 96^{\circ} 13^{\prime} \mathrm{E}\right)$ in the southern part of Gansu An'xi Extremely Arid Desert National Nature Reserve in northwest China. The annual average temperature at the study site from 2010 to 2017 was $9.57^{\circ} \mathrm{C}$ (with extremes of -23.3 to $40.9^{\circ} \mathrm{C}$ ), and the mean annual precipitation was $41.72 \mathrm{~mm}$ (data from a meteorological station constructed in the study area in 2009). The region is a world wind bank with an annual average wind speed of $3.7 \mathrm{~m} / \mathrm{s}$, an instantaneous wind speed of more than $17 \mathrm{~m} / \mathrm{s}$, an average of 137 sandstorms/year, and an annual frost-free period of 138146 days (Liu and Yang 2006). The field work was carried out in patchy wooded area that is composed of Elaeagnus angusifolia (90\%), Populus gansuensis, and Salix matsudana and is surrounded by desert with several areas of croplands.

\section{Field methods}

In this region, the Saxaul Sparrow is a resident species, and the Isabelline Shrike is a summer migrant. A total of 110 artificial nest boxes have been mounted in the wooded area since 2009 for the Saxaul Sparrow, providing a convenient mechanism for collecting breeding parameters. The Isabelline Shrike constructed bowl-shaped nests in the trees, and we searched trees around the study area for their natural nests and inspected them during the breeding period. From April to August 2013 and 2014, 19 nests in the nesting period, 8 nests in the hatching period and 13 nests in the nestling period of the Saxaul Sparrow, and 23 nests in the brooding period of the Isabelline Shrike were monitored, and reproductive behaviour was recorded by a miniature camera (AEE HD50, Shenzhen AEE Technology Co., Ltd) installed 1-1.5 $\mathrm{m}$ away from the nest. To eliminate interference from the camera on bird behaviour, the camera was wrapped in bark, and a simulated camera was hung in the position for several days before actual recording. Each nest was videoed in the same period from 7:00 to 11:00 in the morning. The video was reviewed on a computer to gather and classify information about the behaviours of parent sparrows around the nest. The feeding behaviours of female and male shrikes were observed to calculate their feeding frequency. We also gathered some basic reproductive parameters, including nest-start time, clutch size, brood size, hatching rate, and fledging rate, for the two species.

Classification and definition of Saxaul Sparrow behaviours We categorized Saxaul Sparrow behaviours into three breeding periods: nesting period, hatching period and nestling period. Specifically, the behaviours of parent sparrows around the nest were separated into 13 actions. (1) Nesting: female and male sparrows enter the nest with grass, feathers and other nest materials during the nesting period; (2) nest-inspecting: the parents enter the nest within $10 \mathrm{~s}$ without any nest material and get out immediately during the nesting and hatching period; (3) nest-tidying: the parents enter the nest for more than $10 \mathrm{~s}$ without any material in the nesting period and stay in the nest for between 10 and $20 \mathrm{~s}$ with no materials during the hatching period; (4) adding nest-material: parent birds carry grass, feathers and other materials into their nest during the hatching period; (5) removing nestmaterial, the parent sparrows remove nest material from the nest during the hatching period; (6) incubating: the parents enter the nest for more than $20 \mathrm{~s}$ in the hatching period; (7) expelling: the parents drive away other same species who enter the nest region by chirping, chasing, etc.; (8) warning: the parents jump around the nest box and pay close attention to the surroundings; (9) waiting: one of the parent sparrows waits for access to food when its mate feeds the nestlings; (10) removing faeces: the parents remove faeces of nestlings from the nest during the nestling period; (11) preening: the adult sparrows comb their own feather using bill and claws nearby the nest box; (12) feeding: the parents carry food in mouth into the nest box; (13) chirping: the parents call and sing around the nest box.

\section{Data analysis}

All of the behavioural data collected from the video were entered into Excel 2016 and then analysed using SPSS 
(19.0). For the Saxaul Sparrow data, the paired-sample $t$ test was used to compare the differences in the frequencies of various actions around the nest boxes carried out by the male and female parent birds from the nesting period to the hatching period to the breeding period. For the Isabelline Shrike data, the paired-sample $t$ test was used to test whether there were differences in the feeding rate between the male and female parent birds. To test whether and how the parental feeding rate was influenced by some factors, we constructed a generalized linear mixed model (GLMM) for the parental feeding rate of the Isabelline Shrike. In each model, parental feeding rate was chosen as the target variable; brood size, nestling age and nest-beginning were the covariates; and sampling year and nest ID were random effects. We presented the means \pm standard error and considered results significant at the $P<0.05$ level and extremely significant at the $P<0.001$ level.

\section{Results}

Behavioural differences between male and female Saxaul Sparrows during nesting period

We obtained $220 \mathrm{~h}$ video on the behaviours of 19 pairs of Saxaul Sparrows in the nesting period. In this period, seven kinds of action, including nesting (14.51\%), nest inspecting (6.97\%), nest tidying (21.12\%), preening
(9.58\%), chirping (12.55\%), expelling (0.29\%) and warning (25.91\%), were recorded and classified (Table 1). Among these actions, warning and nest tidying were the most frequent behaviours performed by parent birds. By comparing the frequencies of these actions between males and females, we found that in comparison to the females, the males conducted nest tidying $(t=-3.085, \mathrm{df}=49$, $P<0.05)$, preening $(t=-5.523, \mathrm{df}=49, P<0.001)$, chirping $(t=-8.360, \mathrm{df}=49, P<0.001)$, and warning $(t=-2.824, \mathrm{df}=49, P<0.05)$ significantly more frequently; in addition, males also conducted other activities more than females, but the differences did not reach the significant level.

\section{Behavioural differences between Saxaul Sparrow females and males during the hatching period}

From the $96 \mathrm{~h}$ of video of the 8-nest Saxaul Sparrow in the hatching period, eight kinds of actions were identified (Table 2). Specifically, incubating (37.54\%) and warning behaviours (33.72\%) occurred the most frequently. Comparing the differences in the frequencies of these actions, in comparison to the females, the males significantly more frequently conducted warning $(t=-3.188, \mathrm{df}=$ $23, P<0.05)$, preening $(t=-3.330, \mathrm{df}=23, P<0.05)$ and chirping $(t=-2.719, \mathrm{df}=23, P<0.05)$ behaviours, but there were no significant differences among

Table 1 Frequencies of Saxaul Sparrow parental actions in the nesting period

\begin{tabular}{|c|c|c|c|c|}
\hline Parents' behaviours & Female & Male & $95 \% \mathrm{Cl}$ & $P$ \\
\hline Nesting & $3.82 \pm 0.498$ & $3.92 \pm 0.486$ & $-1.531-1.331$ & 0.889 \\
\hline Nest inspecting & $0.78 \pm 0.179$ & $1.08 \pm 0.151$ & $-0.749-0.149$ & 0.186 \\
\hline Nest tidying & $1.48 \pm 0.207$ & $2.26 \pm 0.180$ & -1.288 to -0.272 & 0.003 \\
\hline Preening & $0.76 \pm 0.109$ & $1.84 \pm 0.184$ & -1.473 to -0.687 & $<0.001$ \\
\hline Chirping & $0.66 \pm 0.127$ & $2.74 \pm 0.252$ & -2.580 to -1.580 & $<0.001$ \\
\hline Expelling & $0.02 \pm 0.020$ & $0.06 \pm 0.034$ & $-0.120-0.040$ & 0.322 \\
\hline Warning & $3.02 \pm 0.247$ & $4.00 \pm 0.270$ & -1.677 to -0.283 & 0.007 \\
\hline
\end{tabular}

$P$ values at significant levels are shown in italics, which applies also to Tables $2,3,4$

Table 2 Behavioural comparison of Saxaul Sparrow parents in the hatching period

\begin{tabular}{lcccc}
\hline Parents' behaviours & Female & Male & 95\% Cl & $\boldsymbol{P}$ \\
\hline Nest inspecting & $0.08 \pm 0.083$ & $0.38 \pm 0.157$ & -0.675 to 0.092 & -0.621 to 0.204 \\
Nest tidying & $0.17 \pm 0.098$ & $0.38 \pm 0.157$ & -1.340 to 3.007 & 0.129 \\
Incubating frequency & $8.33 \pm 0.882$ & $7.50 \pm 0.514$ & -3942.852 to 2807.936 \\
Incubating time (s) & $3384.54 \pm 318.797$ & $4452.00 \pm 1604.916$ & -1.549 to 1.716 & 0.436 \\
Adding material & $2.83 \pm 0.374$ & $2.75 \pm 0.581$ & -0.130 to 0.463 & 0.731 \\
Removing material & $0.21 \pm 0.134$ & $0.04 \pm 0.042$ & -5.977 to -1.273 & 0.917 \\
Warning & $7.00 \pm 0.651$ & $10.63 \pm 0.911$ & -2.972 to -0.694 & 0.004 \\
Preening & $0.96 \pm 0.266$ & $2.79 \pm 0.548$ & -2.934 to -0.399 & 0.003 \\
Chirping & $0.29 \pm 0.127$ & $1.96 \pm 0.569$ & & 0.012 \\
\hline
\end{tabular}


the other actions. The males took part in incubation and didn't show significant differences with the females in incubating frequency and time.

\section{Behavioural differences between Saxaul Sparrow females and males during the nestling period}

The behaviour of parent Saxaul Sparrows during the nestling period ( $266 \mathrm{~h}$ of behavioural statistics for 13 nests) was divided into six specific actions (Table 3). Among these behavioural actions, feeding nestlings (63.04\%) was the most frequent action taken by parents, followed by warning $(23.86 \%)$ in this period. Furthermore, in comparison to the females, the males conducted significantly more feeding $(t=-2.962$, df $=47, P<0.05)$, warning $(t=-7.279, \mathrm{df}=47, P<0.001)$, chirping $(t=$ -3.413 , df $=47, P<0.05)$, waiting $(t=-3.726$, df $=$ $47, P<0.05)$ and preening $(t=-2.101, \mathrm{df}=47, P$ $<0.05)$ behaviours, but the female cleared faeces of the nestlings $(t=3.077, \mathrm{df}=47, P<0.05)$ more frequently.

\section{Difference between Isabelline Shrike females and males in feeding rates}

In this study, data on 23 breeding nests of the Isabelline Shrike were collected with $5.12 \pm 0.66$ eggs and $3.70 \pm$ 1.33 nestlings per nest. The hatching rate was $69.00 \%$, and the fledging rate was $96.53 \%$. Simultaneously, the $t$ test showed that the clutch size was significantly larger than the brood size $(t=6.255, \mathrm{df}=24, P<0.001)$, and there was no significant difference between the brood size and the number of fledglings $(t=1.365, \mathrm{df}=24, P>0.05)$.
We recorded $3264 \mathrm{~h}$ of video on the breeding activity of parent shrikes and then analysed the differences in feeding rates between the males and females. The feeding rate of the males (9.04 \pm 4.814 times per hour) was significantly higher than that of the females $(4.55 \pm 4.772$ times per hour; $t=-8.20, \mathrm{df}=135, P=0.00)$.

The generalized linear mixed model (GLMM) analysis of the possible factors affecting the feeding rates of the parent Isabelline Shrikes showed that there was a positive correlation between parent-bird feeding times and brood size $(P<0.001)$, which means that parents feed more prey to nestlings when there are more nestlings (Table 4). Furthermore, there was a positive correlation between female-bird feeding times and nestling age $(P<0.001)$, and a negative correlation between male bird feeding times and nestling age $(P<0.001)$, which means that the feeding frequency of female parent birds increased as nestlings grew older and the feeding frequency of male parent birds decreased. In addition, the male-bird feeding rate was significantly affected by the nest-beginning time $(P<0.001)$, which means that the earlier the reproduction, the higher the male feeding rate (Table 4 ).

\section{Discussion}

Reproductive investment of males is greater than that of females in Saxaul Sparrows

The frequency of warning and chirping behaviours in the male sparrows was significantly higher than that in the female sparrows from the nesting period to the nestling period, and together, these two actions could be called

Table 3 Saxaul Sparrow parent action frequency in the nestling period

\begin{tabular}{|c|c|c|c|c|}
\hline Parents' behaviours & Female & Male & $95 \% \mathrm{Cl}$ & $P$ \\
\hline Feeding & $23.31 \pm 2.520$ & $29.33 \pm 2.518$ & -10.110 to -1.932 & 0.005 \\
\hline Warning & $4.73 \pm 0.733$ & $14.02 \pm 1.578$ & -11.860 to -6.724 & $<0.001$ \\
\hline Faeces-clearing & $3.92 \pm 0.610$ & $1.96 \pm 0.365$ & $0.678-3.239$ & 0.003 \\
\hline Preening & $0.23 \pm 0.150$ & $0.77 \pm 0.202$ & -1.060 to -0.023$)$ & 0.041 \\
\hline Chirping & $0.06 \pm 0.46$ & $1.02 \pm 0.280$ & -1.523 to -0.393$)$ & 0.001 \\
\hline Waiting & $0.38 \pm 0.145$ & $1.31 \pm 0.302$ & -1.444 to -0.431$)$ & 0.001 \\
\hline
\end{tabular}

Table 4 Relationship between parental feeding rate, brood size, nestling age and nest-beginning time for the Isabelline Shrike

\begin{tabular}{llcccc}
\hline Model & Fixed effect & $B \pm$ SE & $\boldsymbol{t}$ & $\boldsymbol{P}$ & $\mathbf{9 5 \% C l}$ \\
\hline Female feeding rate & Brood size & $1.108 \pm 0.145$ & 7.639 & $<0.001$ & $0.821-1.394$ \\
& Nestling age & $0.481 \pm 0.050$ & 9.552 & $<0.001$ & $0.381-0.580$ \\
& Nest-beginning time & $0.012 \pm 0.015$ & 0.813 & 0.418 & -0.017 to 0.042 \\
Male feeding rate & Brood size & $1.174 \pm 0.158$ & 7.412 & $<0.001$ & $0.861-1.487$ \\
& Nestling age & $-0.073 \pm 0.069$ & -2.493 & 0.014 & -0.310 to -0.036$)$ \\
& Nest-beginning time & $-0.047 \pm 0.014$ & -3.343 & $<0.001$ & -0.074 to -0.019 \\
\hline
\end{tabular}


field protection, which means that field protection is mainly the responsibility of male individuals in the pairs of birds.

During the nesting period, the nest-building job was mainly performed by males of most social monogamy birds. Behaviours of the Passer birds which live and reproduce in some moisture- and climate-stable areas show similar trends that the nests were built almost by the males alone. For instance, the nests of Spanish Sparrows (P. hispaniolensis) are almost always constructed by males (Summers-Smith 1989), and the male House Sparrows (P. domesticus) are responsible for nesting and building nests alone before finding a mate in Calgary, Canada (McGillivray 1983). Unlike these species, the couples of Desert Sparrows (P. simplex) that live in desert region of Turkmenistan construct nests together (Sopyev 1965), and the Saxaul Sparrow as shown by our results that the nesting work was also carried out by the male and female parent birds together, and the frequency of nesting actions was essentially no different. This may be a common feature of the reproductive investment of birds living in desert environments during nesting periods.

Related studies have shown that House Sparrow, Spanish Sparrow, and Dead Sea Sparrow (P. moabiticus) females are responsible for egg incubation (Gavrilov 1963; Summers-Smith 1989). Although both female and male Desert Sparrows are involved in incubation, the hatching frequency times are two-fold greater for females than for males (Sopyev 1965). In contrast, in the Saxaul Sparrow, both parents participated in egg incubation, and there was no significant difference between the females and males in terms of the frequency and duration of hatching. Moreover, our results showed that in comparison to the female Saxaul Sparrows, the male Saxaul Sparrows not only devoted more time and energy to warning, preening and chirping behaviours during the hatching period but were also involved in egg hatching and were no different from females, which means that male Saxaul Sparrows invested more in the family in this period. In our study area, the temperature varies greatly in the breeding season, and it is often windy and sandy. The early morning temperature is often below $13{ }^{\circ} \mathrm{C}$, and the average temperature of embryonic development of eggs is $28.89{ }^{\circ} \mathrm{C}$ (measured in this study). Therefore, rotating female and male hatching behaviours could ensure that the incubation temperature is not too low and may partly account for the hatching rate of Saxaul Sparrows reaching $81.99 \%$ (measured in this study), which is far higher than that of Desert Sparrows and Dead Sea Sparrows living in desert habitats (their hatching rates were $44 \%$ and $42 \%$, respectively) (Summers-Smith 1989).

In the nestling period, in comparison to the female Saxaul Sparrows, the male Saxaul Sparrows also had higher reproductive input, which was embodied in the fact that males possessed a significantly higher frequency of warning, preening, chirping and waiting behaviours than females. In particular, in comparison to the females, the males provided more food to nestlings. Due to the apparently high feeding input by the male parent Saxaul Sparrow, there was a higher fledging rate for this species $(91.92 \%)$ than for other species. In contrast, only $68 \%$ of the Dead Sea Sparrow nestlings fed by the female parent fledged (Yom-Tov and Ar 1980), and when female and male Spanish Sparrows and Desert Sparrows provide prey for offspring together and equal in frequency, $62.3 \%$ (Gavrilov 1963) and 76\% (Sopyev 1965) of the nestlings fledged, respectively.

\section{Male feeding rate was higher than the female feeding rate in Isabelline Shrikes}

As one of the most critical stages in the whole reproductive process of altricial birds, feeding is directly related to the survival and health of nestlings. In addition, the feeding inputs can partly reflect the reproductive investment of male and female parent birds. Previous studies of feeding input differences between females and males in some socially monogamous birds have shown that, in general, the average feeding rate of females was higher than that of males or generally equal. For instance, the feeding frequency of the male Savannah Sparrow (Passerculus sandwichensis) accounts for only $24-40 \%$ of the total feeding frequency, which is significantly lower than that of females (Freeman-Gallant 1998). Another study of Great Tit (Parus major) showed that there was no significant difference in the feeding rates between females and males (Bengtsson and Rydén 1983). In addition, in the Loggerhead Shrike (Lanius ludovicianus), a species of shrike living in Central and North America, males and females also have similar feeding rates (Miller 1931; Gawlik et al. 1991). However, in our study, there was a significant difference $(t=-8.20, \mathrm{df}=135, P<0.001)$ in the feeding rates of female and male Isabelline Shrikes that bred in the same area as the Saxaul Sparrow. Specifically, male feeding rates were approximately twice as high as those of females, and perhaps because of this, the fledging rate of the Isabelline Shrike nestlings was 96.53\%, with a $69.00 \%$ hatching rate.

With the growth of nestlings, the feeding rates of males decreased and those of females increased at the same time. After the last breeding period, the male and female parent birds had similar feeding rates. One bird in a pair would increase its breeding input for compensation when the other in the pair reduced its role in caring for nestlings, when the nestlings were cared for by both parents (Wright and Cuthill 1989; Houston et al. 2005). Therefore, with a decrease in the male feeding rate, the female 
bird increases its feeding rate to meet the growth needs of their nestlings. Another reason for the change in male and female feeding rates in the daytime may be related to their division of work during the nestling period. Specifically, when the newly hatched squabs were naked with no down, their female parent always covered the nest to keep them warm or keep the sun off them, so the female parent did not spend much time and energy catching prey for the squabs. Along with the organs of the nestlings gradually developed, and their feathers gradually plumped with increasing nestling age (Xu 2002; O'Connor 2008; Zhang 2009), they no longer needed the female parent to be in the nest to provide these and the female could spend more energy and time on feeding behaviours.

With the increase in brood size, both the male and female Isabelline Shrike parent birds increased their feeding rates, which means that the parents played a role in the prey available to support more fledglings. This strategy could maximise their present reproductive benefits.

\section{Males passerine birds living in harsh desert environments may increase their reproductive investments}

The effort parent birds put into feeding is affected by the ecological environment of the breeding area (Aho et al. 2009). Two studies on parent-breeding input were carried out in two areas with extremely different environments for the House Sparrow. One study showed that the male feeding rates were lower than female feeding rates in temperate climate areas with sufficient food resources (Bédard and Meunier 1983), and the other study showed that there was no significant difference in feeding input between male and female parent birds breeding in places with less food (Hegner and Wingfield 1987). When the environment of a breeding area is poor, such as at high altitudes, parents, especially males, increase their feeding input to subsequent generations to compensate for the negative influence of environmental factors on reproduction in birds and mammals (Badyaev 1997; Wynne-Edwards 1998). In birds, the average feeding frequency of male parent birds breeding in high-altitude areas is $55.6 \%$ of the total average feeding frequency, which is significantly higher than that in low-altitude areas (Ghalambor 2001). Another study of reproductive investment in the Grey-capped Greenfinch (Carduelis sinica) showed that the total male input increased as the elevation of the breeding region increased during the breeding period (Badyaev 1997). In conclusion, the reproductive success rates of birds that breed in highaltitude regions are mainly dependent on the investments by males (Lyon et al. 1987; Badyaev 1997). In our study area, the early period in the breeding season (April-May) was characterized by lower temperatures, less precipitation, inconsistent and extreme weather conditions, and even sandstorms (Liu and Yang 2006). Deserts are known for their droughts, gales, changing climates and extreme weather, which make them severely unstable ecological environments. Therefore, in comparison to the female Saxaul Sparrows, the male Saxaul Sparrows provided higher amounts of input during the three periods of reproduction, while the male Isabelline Shrikes possessed higher feeding rates than those of the females, which could be a common characteristic and an adaptation to the harsh desert environment. However, these two passerine birds are very different in terms of their life history characteristics and habits. Therefore, we think that male parent birds increase their reproductive investment and that this could also occur in other passerine birds breeding in hash desert regions. This is a reproductive strategy for birds to adapt to these adverse and changing conditions and ensure sufficient reproductive output.

\section{Acknowledgements \\ The authors are very grateful to Liang Wang for providing help in the field, Dr. Li Ding for teaching us to analyse data, and the management staff of Gansu An'xi Extremely Arid Desert National Nature Reserve for allowing us to conduct this study in this area.}

\section{Authors' contributions}

$X B$ designed the experiments and refined this manuscript, $X Z$ and $X Y$ collected the field data, DM developed this manuscript and conducted the data analysis, ML developed most of the data summary, and ZC and XD reviewed the video and recorded the data in Excel. All authors read and approved the final manuscript.

\section{Funding}

Financial support was provided by the National Natural Science Foundation of China (Grants 31672296 and 31172104 ).

Availability of data and materials Not applicable.

\section{Declarations}

\section{Ethics approval and consent to participate}

Animals were treated in accordance with the guidelines of the Ethics Committee of the School of Life Sciences, Lanzhou University, that specifically approved this study.

\section{Consent for publication}

Not applicable.

\section{Competing interests}

The authors declared that they have no competing interests.

Received: 4 November 2020 Accepted: 28 June 2021

Published online: 06 July 2021

\section{References}

Aho T, Kuitunen M, Hakkari T, Suhonen J, Jäntti A. Effects of male removal on reproductive success and provisioning in the Eurasian Treecreeper (Certhia familiaris). Ornis Fennica. 2009;86:1-10.

Badyaev AV. Altitudinal variation in sexual dimorphism: a new pattern and alternative hypotheses. Behav Ecol. 1997;8:675-90.

Bédard J, Meunier M. Parental care in the Savannah sparrow. Can J Zool. 1983:61:2836-43. 
Bengtsson $\mathrm{H}$, Rydén $\mathrm{O}$. Parental feeding rate in relation to begging behavior in asynchronously hatched broods of the great tit Parus major. Behav Ecol Sociobiol. 1983;12:243-51.

Freeman-Gallant CR. Fitness consequences of male parental care in Savannah sparrows. Behav Ecol. 1998;9:486-92.

Gavrilov El. The biology of the Eastern Spanish Sparrow, Passer hispaniolensis transcaspicus tschusi, in Kazakhstan. J Bombay Nat Hist Soc. 1963;60:301-17.

Gawlik DE, Papp J, Bildstein KL. Nestling diet and prey-delivery rates of Loggerhead Shrikes (Lanius /udovicianus) in north-central South Carolina. Chat. 1991;55:1-5

Ghalambor BCK. Evolution of life histories along elevational gradients: tradeoff between parental care and fecundity. Ecology. 2001:82:2948-60.

Gross MR. The evolution of parental care. Q Rev Biol. 2005;80:37-46.

Hegner RE, Wingfield JC. Effects of brood-size manipulations on parental investment, breeding success, and reproductive endocrinology of House Sparrows. Auk. 1987;104:470-80.

Horváthová T, Nakagawa S, Uller T. Strategic female reproductive investment in response to male attractiveness in birds. P Roy Soc B-Biol Sci. 2012;279:163-70.

Houston Al, Székely T, McNamara JM. Conflict between parents over care. Trends Ecol Evol. 2005;20:33-8.

Liu NF, Yang ZW. Report on second scientific investigation of Anxi Desert National Reserve in Gansu. Lanzhou: Lanzhou University Press; 2006.

Lyon $\mathrm{BE}$, Montgomerie RD, Hamilton LD. Male parental care and monogamy in snow buntings. Behav Ecol Sociobiol. 1987;20:377-82.

McGillivray WB. Intraseasonal reproductive costs for the House Sparrow (Passer domesticus). Auk. 1983;100:25-32.
Miller AH. Systematic revision and natural history of the American shrikes (Lanius). Univ California Publ Zool. 1931;38:11-242.

O'Connor RJ. Differential growth and body composition in altricial passerines. Ibis. 2008;119:147-66.

Parish DM, Coulson JC. Parental investment, reproductive success and polygyny in the lapwing, Vanellus vanellus. Anim Behav. 1998;56:1161-7.

Sanz JJ, Kranenbarg S, Tinbergen JM. Differential response by males and females to manipulation of partner contribution in the great tit (Parus major). J Anim Ecol. 2000;69:74-84.

Sopyev O. The desert sparrow in the Kara Kum. Ornitolgiya. 1965;7:134-41.

Summers-Smith JD. The sparrows: a study of the genus Passer. Calton: T \& AD Poyser; 1989.

Trivers RL. Parental investment and sexual selection. Venice: Aldine; 1972.

Trivers RL. Parent-offspring conflict. Am Zool. 1974;14:249-64.

van Noordwijk AJ, de Jong G. Acquisition and allocation of resources: their influence on variation in life history tactics. Am Nat. 1986:128:137-42.

Wright J, Cuthill I. Manipulation of sex differences in parental care. Behav Ecol Sociobiol. 1989;25:171-81.

Wynne-Edwards KE. Evolution of parental care in Phodopus: conflict between adaptations for survival and adaptations for rapid reproduction. Am Zool. 1998:38:238-50.

$\mathrm{Xu} \mathrm{Q}$. The magpie nestling's growth development and thermoregulatory capacity. J Northeast Forest Univ. 2002;30:38-41.

Yom-Tov Y, Ar A. On the breeding ecology of the Dead Sea sparrow, Passer moabiticus. Zoology. 1980;29:171-87.

Zhang JW. The nestling growth of Common Kestrel (Falco tinnunculus). Master's Thesis. Changchun: Northeast Normal University; 2009.
Ready to submit your research? Choose BMC and benefit from:

- fast, convenient online submission

- thorough peer review by experienced researchers in your field

- rapid publication on acceptance

- support for research data, including large and complex data types

- gold Open Access which fosters wider collaboration and increased citations

- maximum visibility for your research: over 100M website views per year

At BMC, research is always in progress.

Learn more biomedcentral.com/submissions 